\title{
Concentration of health care providers: does it contribute to integration of service delivery?
}

This article was published in the following Dove Press journal:

Risk Management and Healthcare Policy

\section{Sheiman \\ $\checkmark$ Shevsky}

Department of State and Municipal Administration, The National Research University Higher School of Economics, Moscow, Russia
Correspondence: I Sheiman

The National Research University Higher

School of Economics, 20 Myasnitskaya

Street, Moscow, Russia, 101000

$\mathrm{Tel}+74956120142$

Email igor.sheim@g23.relcom.ru
Background: The concentration of health care providers is a growing process in many countries, including Russia. There is a general expectation that larger medical entities can better promote the process of service integration.

Purpose: This paper explores the impact of health provider concentration on service delivery integration through the indicators of teamwork, coordination and continuity of care in outpatient and inpatient medical facilities. These developments in Russia are compared with international experience.

Methods: National and international literature on health services concentration and integration is reviewed; statistical analysis is based on Russian national data, WHO and OECD databases; a sociological survey of Russian physicians and interviews with managers of medical facilities are used to evaluate the value of integration.

Results: The review of international trends indicates a growing process of mergers to form large hospital and physician-hospital systems, particularly in the USA. Enhanced clinical and administrative integration is usually seen as the logical outcome of concentration. However, growing international empirical estimates demonstrate a controversial impact of concentration on quality of medical care, unit cost (per patient) and integration of care. In Russia, the establishment of consolidated health systems is coupled with an increase in the average size of hospitals, while the number of free-standing providers has substantially decreased. The effect of concentration in the country is also controversial. There is some evidence of its positive impact on restructuring service delivery and the accessibility to some services, but the surveys of physicians don't demonstrate improvement in the organization of service delivery, nor closer links between providers. Surveys of providers don't provide evidence of teamwork, coordination and continuity of care in consolidated settings.

Conclusion: There are many deeply rooted barriers to integration in Russia, of which the most important is the lack of clear objectives of providers mergers. The major lesson learnt is that in the country with limited financial resources, decisions on provider concentration should be carefully justified with the focus on the specific integrative activities. National health policy for integration should be a major pre-condition for the positive impact of concentration on integration.

Keywords: concentration of health providers, integration of service delivery, Russian health care, teamwork, coordination of care, continuity of care

\section{Introduction}

The concentration of health care providers is a growing process in many countries. It takes various forms - mergers, acquisitions, alliances, partnerships - each with differing degrees of integration of service delivery. There is a general expectation that larger medical entities (hospital groups, hospital-physician systems, etc.) can better promote the process of combining regular preventive and curative functions 
within medical organizations and between them for solving joint problems. ${ }^{1}$ Integration in health sector is generally described as a process covering not only clinical activities, but also funding, management and organization of service delivery with the aim of reaching close interaction of providers. ${ }^{2}$ Some authors identify the major attributes of service integration - teamwork, coordination and continuity of care - and suggest specific indicators to evaluate them. ${ }^{3}$

A substantial body of literature is focused on the study of concentration and integration of health care as separate developments. Much less attention is paid to the issue of their interrelationship, particularly the impact of concentration on integration. There are many questions that remain unclear: What are the expectations and the actual impact of concentration? What are the pre-conditions for concentration to promote integration of service delivery? Are they actually followed internationally? What should be done to strengthen the impact of concentration on integration?

Most of studies explore concentration and integration in the USA, where concentration is driven mostly by market forces intended to strengthen market (bargaining) power of providers. ${ }^{4,5}$ The problem of integration is also relevant for countries with strong public health systems with a high role of the government in health funding and provision, including post-communist countries. Most of these countries face serious underfunding of health care and are looking for new instruments to strengthen health systems. Concentration of health providers in these countries is increasingly seen as a way to consolidate resources to achieve better access to care, and to bring together a fragmented service delivery. ${ }^{3,6}$ However, the interrelationship between concentration and integration is equally unclear for these countries.

This paper attempts to explore these developments in Russia, the largest post-communist country, and compare them with international experience. Russia spends only $3.5 \%$ of GDP on health care from public sources. It faces several structural problems of service delivery. ${ }^{7}$ These problems now promote the concentration of resources in large medical facilities. The impact of concentration on the outcomes of health system and degree of service integration has become a relevant issue of Russian health policy.

The paper is structured to cover a set of issues. First, international trends in health provider concentration are discussed, with a special focus on the impact of concentration on integration, mostly in the USA. Second, similar processes in Russia are presented and evaluated. Third, the comparative outcomes are discussed with resulting health policy recommendations regarding how to organize the concentration of providers to achieve desired outcomes of service delivery integration.

The method of the analysis includes a review of the national and international literature on health services concentration and integration, as well as materials from the Russian federal and regional ministries of health. Statistical analysis is based on Russian national data. WHO and Organization for Economic Cooperation and Development (OECD) databases are used for comparison of concentration trends in the countries with similar territories as in Russia. A sociological survey of Russian physicians and interviews with managers of medical facilities are used as the method to evaluate the value of integration.

The motivation to produce this paper is to encourage a more careful study of service concentration in Russia and other countries with limited financial resources. Their policy makers seek ways to solve health care problems by increasing the scale and capacity of providers. The major message is that concentration does not automatically yield the benefits of the integration of service delivery. The results opposite to conceptual expectations are possible. Integration is a complex process, which depending on context may or may not be facilitated by the concentration of providers. Carefully designed integrative activities, that is practical actions to strengthen teamwork, coordination and continuity of care, should be the focus of this process by policy makers and managers.

\section{Concentration and integration: international trends, conceptual issues and empirical evidence}

Many countries are pursuing health provider concentration. In the USA, there were nearly 900 announced hospital mergers and acquisitions between 2000 and 2012, and this tendency has accelerated after the Affordable Care Act, which was signed into law in early $2010 .{ }^{8}$ In the United Kingdom, 112 of 223 public hospitals were consolidated in late 1990 to early 2000 . The average hospital market in the region has decreased from 7 to 5 hospitals. ${ }^{9}$ In Germany, around $60 \%$ of public and private hospitals have been consolidated into larger hospital groups. Their share in hospital market increased from $25 \%$ in 2005 to $31 \%$ in $2011 .^{10}$ 
A further dimension of provider concentration is the consolidation of hospitals with outpatient care facilities in various forms. In the USA, the share of hospital-owned physician practices increased from $30 \%$ in 2004 to $55 \%$ in 2009. After the Affordable Care Act, hospitals have been increasingly employing outpatient physicians, in part to position themselves to become Accountable Care Organizations (ACO) which are physician-hospital organizations responsible for the organization of care for defined enrollee populations. In 2016, there were over 400 ACOs with contracts covering around 8 million Medicare beneficiaries. The objectives of these concentrations vary, but most consolidated organizations are expected to strengthen the integration of service delivery. ${ }^{11,12}$

These two trends represent horizontal and vertical models of concentration. The former involves grouping (consolidating) organizations that provide a similar level of care under one management umbrella. Multihospital systems, mergers and strategic alliances with neighboring hospitals are the examples of horizontal integration. The latter involves the coordination of services among operating units that are at different stages of the process of service delivery. In the USA, this model of integration can include acquisitions/alliances with physicians, health plans or health maintenance organizations, long-term care facilities. ${ }^{4}$

Although the context in the USA is radically different to that in Russia, we focus on this country because it faces similar challenges of service delivery fragmentation and is most active in searching the ways to overcome it. There is a substantial number of the emerging integrative models, some of which are based on the presumption that larger entities may contribute to hospital-physician alignment, clinical and financial integration, information continuity and value-driven management. ${ }^{4}$ These models are of particular interest for Russia despite a different health finance and service delivery models.

\section{The lines of potential impact of concentration on integration}

Concentration in the context of health system in the USA usually reflects the response of providers to competitive pressures in increasingly competitive health care market. Some researchers presume that concentration will lead to integration to achieve transaction cost economies, and to be better able to deal with incomplete contracting challenges and economies of scope. Integrated organization is to offer lower prices and become more competitive. ${ }^{13}$
Concentration may also contribute to integration through the formation of a joint culture of teamwork. Hospital-physician systems have the potential to integrate care teams across inpatient and outpatient settings. Enthoven ${ }^{14}$ makes a special point on the joint responsibility for the outcome of care in integrated systems:

The outpatient doctors know what the inpatient doctors are doing to the patient. And decisions are made with the total results, i.e. patient outcomes and total resource use, in mind, and not sub-optimization in one or another silo... Patients are not the "property" of one or another specialist.

The author urges that an effective-integrated system must be large to incorporate the features of integration, and cites the favorable results from the integrative activities in the largest entities, including Kaiser Permanente.

Consolidated medical groups are expected to demonstrate the additional leverage to develop and implement integrated clinical care recommendations and integrated care pathways that determine the movement of patients in a multi-level system of service delivery. It is also easier in these systems to introduce quality measurement and improvement with a focus on the "system" indicators that reflect input from the entire medical system rather than its specific segment. ${ }^{14}$

Large medical entities have an additional opportunity for the consolidation of capital investment resources and their joint use by various providers. They can centralize administrative and support services with a potential decrease in unit cost (per patient). Also, the centralization of management can restructure the network of medical facilities via the closure or changing the scope of medical units; a shift of patients from inpatient to outpatient settings; the procurement of medical equipment and drugs with price discounts; as well as rearranging specific diagnostic and curative functions for the purpose of more effective use of resources. Large settings can also redistribute the resources across geographic areas and sectors of care. These are the common expectations.

With all these potential positive effects of concentration, the overall effect is heavily dependent on the actual scope and style of integration: which units are consolidated; how management changed; the role of financial incentives; what are the actual integrative activities within big medical groups. Centralization can have totally different outcomes in certain market situations. With a lack of competitive pressure, the motivation for the actual integrative activities in large-consolidated settings may be even lower than for independent providers. Gaynor et al. ${ }^{9}$ 
rightfully indicate that mergers may be an inappropriate instrument to improve the outcomes for poorly performed hospitals, because they can weaken competitive pressures to change organizational behavior. Cutler and Morton ${ }^{15}$ admit that big medical groups may improve quality of care due to the growing specialization of care provision and exploitation of economy of scope, but at the same time see the negative aspect of the network's growing market power, particularly potential price increases in highly concentrated markets.

Also, the increased size of hospitals and other providers does not guarantee better service coordination and cooperation among their service units, nor efficiency gains. There is a substantial body of literature with the evidence that after reaching a certain size of hospitals (around 500-600 beds), the potential for decreasing unit cost is constrained due to the complexities of management and other factors. ${ }^{16}$

\section{The empirical evidence of integrated systems performance}

Many studies explore the effect of integrated service delivery systems in the USA. The term "integrated" is usually used for hospital-physician and multi-specialty groups that have a special focus on collaborative or alliance activities rather than formal mergers of providers. The assessment used here is a comparison of performance measures mostly quality of care (disease-specific mortality) and unit cost - with performance indicators for the entire health system or the "Medicare" program.

The randomized control Rand Health Insurance Experiment found that integrated risk-bearing prepaid multi-specialty group practices had 25-30\% lower per capita costs than in the traditional fee-for-service practice. This result is attributed to incentives from prepayment and unified group to use a less expensive style of service delivery in this group. ${ }^{14}$ A similar study by Weeks et al. ${ }^{17}$ compared multi-specialty group practices associated with hospital groups with the average indicators for the specific age/sex groups under the "Medicare" program. The researchers found that the total unit cost was $7.1 \%$ lower in the integrated groups than the average for more loosely affiliated groups.

Shortell and Schmittdiel ${ }^{18}$ found that the availability of close links between physicians and hospitals increased the probability of chronic disease management programs. Large prepaid physician groups can work closely with hospitals in the management of specific chronic cases. Similar results have been found for "Kaiser Permanente," where the frequency of case management is higher than in independent fee-for-service practices. ${ }^{19}$

The systematic review of the research in this area conducted by Hwang et al. ${ }^{20}$ showed that 19 of 21 peerreviewed papers demonstrated higher quality of care provided in integrated medical groups relative to independent providers. The authors also found that these groups reduced costs. A later study by $\mathrm{Schmitt}^{8}$ showed statistically significant cost reductions at acquired hospitals after hospital mergers in the USA. On average, acquired hospitals realize cost savings between $4 \%$ and $7 \%$ in the years following the acquisition.

However, these findings are opposed by other authors. Dranove and Lindrooth ${ }^{21}$ found that the mergers of local hospitals resulted in the short-term decrease in administrative cost (by 14\%) but did not affect the overall cost. Kaul et $\mathrm{al}^{22}$ did not find the relationship between the size of medical systems and unit cost using the data of the Centers for Medicare \& Medicaid Services on 526 medical groups. Similar conclusions are made in the studies of hospital mergers in European countries. ${ }^{23,24}$

A major explanation for such weak performance is that mergers often act as holding companies to collect highly autonomous hospitals and may not integrate the services across organizations and do not use standardized procedures, and joint responsibility for health outcomes. ${ }^{22}$

Cwiek et $\mathrm{al}^{25}$ discuss the effective path and pace for integration. The authors make a point that in medical systems:

Integration may not be the end goal, but rather what results when otherwise unaligned entities try to achieve mutually beneficial interdependence and share financial responsibility for better quality and cost outcomes.

The authors suggest in their evaluation of existing patterns of service delivery that good results are a function of the available resources to invest in the infrastructure of integration and the degree of providers' readiness to implement integrative innovations. With this information in mind, it is recommended that a strategy for integration must have specific steps to enable the effective characteristics of integration. Witt and $\mathrm{Jacobs}^{26}$ indicate that new management structures are also needed to develop a sustainable integration culture that will ensure the joint accountability for enhanced outcome and cost effectiveness. 
Formal consolidation of providers may also result in an unexpected outcome of reduced independence and constrained economic motivation of providers. Therefore, the effectiveness of concentration should be carefully measured by the success of certain integrative activities, rather than short-term savings due to merging administrative and support services. The scope of these activities can be substantial, including the involvement of outpatient physicians in the management of the hospital system; building a joint system of quality management based on joint clinical recommendations; use of integrated patient pathways; better data exchange; greater reliance on multidisciplinary teams of providers who deal with specific chronic cases, with more clearly defined specific patterns of interaction between providers, etc. ${ }^{14,27}$

This empirical research of concentration in the USA does not provide an unambiguous answer to the question about its effect. Contrary to conceptual expectations, large medical groups do not automatically strengthen integration. Size or scale alone may not yield higher levels of performance. Many strategies need to be used together to achieve sustainable gains.

\section{Concentration and integration of service delivery in Russia Basics of health system and the recent trends}

After the collapse of the USSR, Russia has inherited the Semashko model of service delivery with a dominance of public providers. This model has many elements of an integrated system, including the responsibility of district physicians (DPs - the major providers of primary care) for the enrolled population, their gatekeeping function, a joint work of DPs and specialists in big multispecialty outpatient facilities (polyclinics), as well as a multi-level system of service delivery based on the referrals from one level to the next (from small rural and urban polyclinics and hospitals to big district and city hospitals). The complicated clinical cases are treated mostly in big regional hospitals with around 1000 beds. Their clinical capacity is the highest in the region. $^{28}$

The governance of service delivery has traditionally been designed to strengthen the interaction between hospitals and polyclinics. In the USSR, this was done mostly through command-and-control methods of administration. In the post-communist time, the implementation of the integration activities has become much more complicated due to the decentralization of governance and a shift to social health insurance model of finance with purchaser-provider split and fee-for-service method of provider payment. The close interaction of providers, however, has ceased to be the objective of health authorities and health insurers as payers. In addition, primary health care has substantially weakened, with a resulting fragmentation of care. ${ }^{3,6}$

Concentration now is seen as an important instrument to revitalize and strengthen the integrated health system in Russia. Similar to many other countries, it is assumed that large and more consolidated service delivery organization will contribute to better teamwork, coordination, and continuity of care. There are two major trends of concentration in Russia over the last two decades: 1) merging hospitals and 2) merging hospitals with other providers. Merging is the sole form of concentration. Partnerships or strategic alliances of providers ("mild" forms of concentration) are not common in Russia.

The prevailing form of merging hospitals in Russia is the consolidation of small rural hospitals into the structure of bigger city hospitals ("central rayon hospitals") that serve the population of municipal communities (both urban and rural). Also, some city hospitals are merged to form consolidated hospital systems. This trend has resulted in an increase in the average size of hospitals - from 156 beds in 2000 to 225 beds in 2014. In Canada, France and the USA, the size of the average hospital has decreased. In Germany and Australia, it remained relatively constant (Figure 1). The average size of the hospital in Russia is currently substantially higher than in most Western countries.

Merging hospitals with other providers take two major forms. The first is the amalgamation of polyclinics with hospitals to form hospital-polyclinic settings ("combined hospitals") working under joint management. The share of such settings increased from $51 \%$ in 2000 to $64 \%$ in $2016 .{ }^{31}$ The rest of facilities are independent hospitals or polyclinics. The second form of mergers is consolidation of all providers in the specific municipal community ${ }^{32}-$ all hospitals and polyclinics, as well as other medical facilities and support services. The result of these mergers is the establishment of large medical systems that are often the sole providers of health care in communities. Contrary to similar hospital-physician systems in the USA, they are formed only in local and regional areas. National-integrated systems do not exist.

These mega medical complexes have been set up in many regions of the country. Their total number is 


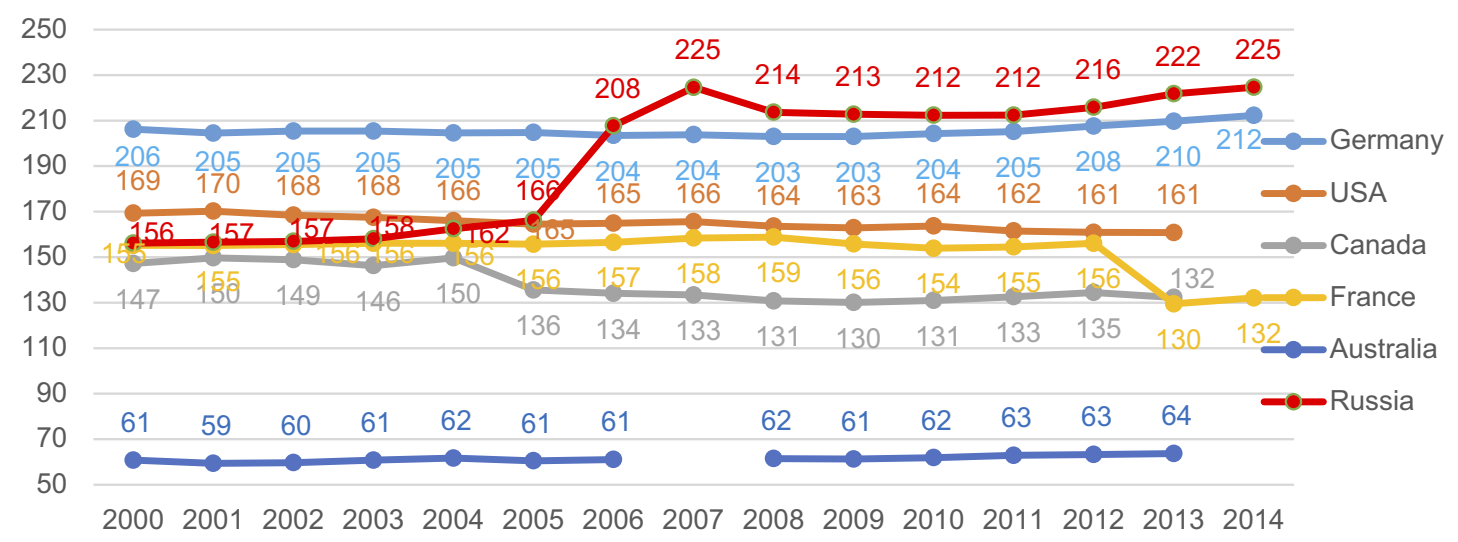

Figure I Trends in the capacity of hospitals in Russia and selected Western countries in 2000-2014 (the number of beds per hospital). Note: Data from OECD and Federal statistical service of the Russian Federation. ${ }^{29,30}$

unknown. In Moscow oblast (the region located around Moscow), each municipal community has a medical complex. One example is Korolev community medical complex that combines four hospitals, all polyclinics and selected other medical facilities. It is the sole health provider that serves a population of 220 thousand residents. ${ }^{33}$ Another example is the consolidation of all polyclinics in Moscow city. All local polyclinics have merged into a few large outpatient centers. Each center combines 5-7 big local polyclinics and serves $250-300$ thousands of adult population. $^{34}$

As a result of these mergers, the overall number of medical facilities decreased by $60 \%$ over the period of 2000-2014, most radically - the number of inpatient settings. It is estimated that the average municipal community now has only 1.5 medical facilities, including 1.4 hospitals and 3.5 polyclinics (Table 1). In many communities, only one medical entity is left.

Concentration trends in Russia are similar to international developments. But it is much less driven by the willingness of providers to strengthen their market power. The major motivation is to enable stronger management of medical facilities in order to accelerate structural changes in service delivery.

\section{Effect of concentration}

\section{Method and data}

The rigorous analysis of concentration effect in Russia, as it has evolved in Western countries, is complicated by a lack of data on unit cost and health outcomes in

Table I The number of public medical organizations in Russia in 2000-2014

\begin{tabular}{|c|c|c|c|c|c|c|}
\hline & \multirow[t]{2}{*}{2000} & \multirow[t]{2}{*}{2014} & \multirow{2}{*}{$\begin{array}{l}2014 \text { to } \\
2000, \%\end{array}$} & \multicolumn{2}{|l|}{2014} & \multirow{2}{*}{$\begin{array}{l}\text { Average number of } \\
\text { medical organizations } \\
\text { per municipal } \\
\text { community }\end{array}$} \\
\hline & & & & $\begin{array}{l}\text { Number of medical organi- } \\
\text { zations in municipal com- } \\
\text { munities (districts and city } \\
\text { districts) }\end{array}$ & $\begin{array}{l}\text { Number of } \\
\text { municipal } \\
\text { communities }\end{array}$ & \\
\hline $\begin{array}{l}\text { Total number of medical } \\
\text { organizations }\end{array}$ & 17,627 & 7098 & 40.3 & 3519 & 2346 & 1.5 \\
\hline Number of hospitals & 9946 & 4865 & 48.3 & 3236 & 2346 & 1.4 \\
\hline $\begin{array}{l}\text { Number of out-patient } \\
\text { organizations (independent } \\
\text { and a part of the combined } \\
\text { hospitals) }\end{array}$ & 17,689 & 11,376 & 64.3 & 8171 & 2346 & 3.5 \\
\hline $\begin{array}{l}\text { Number of independent out- } \\
\text { patient organizations (with- } \\
\text { out dental) }\end{array}$ & 6306 & 2233 & 35.4 & 1139 & 2346 & 0.5 \\
\hline
\end{tabular}

Note: Sourced from The Russian Federation Ministry of Health. [resources and Health Facilities Activity. Moscow: Statistical Handbook; 20I6. Available from: https://www. fedstat.ru/indicator/31557.do. Accessed September 26, 2018 [in Russian]. ${ }^{31}$

${ }^{a}$ Without dental offices. 
consolidated systems, as well as by a small number of independent medical organizations as control units. Therefore, this analysis is a review of qualitative processes on the basis of available data. First, we evaluate the impact of concentration on the process of service restructuring to achieve better access to care in selected Russian regions. The regional statistical data is used. Second, we compare the major dimensions of integration - teamwork, coordination and continuity of care - in consolidated hospitalpolyclinic settings and in independent facilities.

The sociological survey of 1500 physicians from three Russian regions (Kaluga, Vologda and Tomsk) is used. The data were collected and processed by the Russian center for public opinion research under a contract with the National Research University Higher School of Economics. ${ }^{3}$ Half of the respondents are the employees of consolidated settings (hospital-polyclinic), and half employees of independent facilities. The sample is representative of the health care structure in terms of the share of various types of providers: $50 \%$ of respondents provide outpatient care, $43 \%$ - inpatient care, $7 \%$ - other services. The response rate is around $95 \%$.

A list of 68 closed questions related to the attributes of integration was developed. The questions on teamwork are focused on the interaction between physicians from various medical facilities. The questions on continuity of care are designed to evaluate the progress of patients through health system. A coordination of care is explored through an evaluation of the coordinating role of primary care providers.

In addition, a survey of DPs is used to assess the comprehensiveness of primary health care and a "gatekeeping" function of DPs. A list of questions was distributed through the Russian social network Vkontakte in May 2016. DPs were asked to estimate the share of primary care visits to specialists without prior referral of DP; 171 DPs from 14 regions of the country responded to these questions.

Managers were also interviewed at large consolidate health systems in Moscow city and Moscow oblast (the area around the capital). Four managers of large outpatient systems and 10 managers of hospital-polyclinic entities were engaged to access the level of integration following large concentration campaigns. Thus, a descriptive analysis is supplemented with insights from a survey and interviews.

\section{Findings of the effect}

The major positive result of Russian concentration is the increased opportunity for the resource redistribution. In consolidated settings, it is relatively easier to close small inefficient units, and centralize some curative, diagnostic and support services. For example, the merger of medical facilities in the Korolev community has allowed the establishment of centralized bookkeeping; an enhanced personnel office; laboratory services; and expanded radiation diagnostics, hemodialysis, CT and MRT units. The capacity of these services is more effective than before, because the working hours and number of patients they serve have substantially increased. The deficit of clinical and support personnel working in these structures has reduced. ${ }^{33}$

Performance from concentration is also evident in the accelerated shift of care from inpatient to outpatient facilities. Large medical systems activated the process of downsizing the capacity of hospitals and increasing the efficiency of hospital beds use. The average length of stay in city hospitals decreased by $23 \%$ in $2000-2016$, the actual use of hospital beds during a year - by $5 \%$, the bed turnover - by $50 \%$ (Table 2). These trends have resulted from both concentration processes and the general restructuring policy of the government. It sets health care utilization targets with the focus on decreasing volumes of inpatient care, and providers must follow these targets.

A shift of patients from inpatient to outpatient facilities has saved some resources. The savings have been used to mitigate the deficit of some services and to weaken explicit and implicit rationing common in Russian medical facilities. $^{35}$

Concentration has also contributed to the use of integrated care pathways and helps strengthen a multi-level of service provision. In Moscow city, outpatient care was divided into three levels. Primary care is provided by DPs

Table 2 City hospitals capacity and its utilization in 2000-2016 in Russia

\begin{tabular}{|c|c|c|c|c|}
\hline & 2000 & 2005 & 2010 & 2016 \\
\hline $\begin{array}{l}\text { Number of hospital beds per } \\
10,000 \text { residents }\end{array}$ & 115.0 & 110.9 & 93.8 & 81.6 \\
\hline $\begin{array}{l}\text { Average length of hospital stay } \\
\text { (days) }\end{array}$ & 14.8 & 13.1 & 12.0 & 11.5 \\
\hline $\begin{array}{l}\text { Utilization of hospital beds during } \\
\text { a year (days) }\end{array}$ & 320 & 321 & 333 & 333 \\
\hline $\begin{array}{l}\text { Hospital beds turnover (number of } \\
\text { patients a year) }\end{array}$ & 22.2 & 27.6 & 31.3 & 35.3 \\
\hline
\end{tabular}

Source: Ref.

Note: Sourced from The Russian Federation Ministry of Health. [resources and Health Facilities Activity. Moscow: Statistical Handbook; 2016. Available from: https://www.fedstat.ru/indicator/31557.do. Accessed September 26, 2018 [in Russian]. ${ }^{30}$ 
and 3-4 categories of specialists, while most of specialists have been centralized in a limited number of polyclinics of the second level, and they have become more accessible to the enrollees of all polyclinics of the first level. The third level is formed by hospitals in their outpatient units. The most complicated ambulatory cases are referred to this level. Managers of larger outpatient centers are responsible for the allocation of specialists among the three levels. The focus of management is to facilitate the movement of patients across these levels of service delivery.

After the start of the new arrangement in 2013, patients have enhanced access to specialists staffed in all structural units of outpatient centers rather than those close to their residence. Similar rationalization is more evident for expensive diagnostic resources (CT, MRT). They are now concentrated in a few polyclinics, and are used more intensively. As a result, the average waiting time for specialists' consultations went down by 2-3 times in 2010-2015; for CT - 4 times; MRT - more than 3 times. ${ }^{34}$ The disadvantage of this process is that some patients have to spend more time to reach the place of service provision.

Another positive effect of concentration in Moscow city is the decrease in administrative cost of around 1 billion roubles a year in 2014-2015 (330 mln USD). Around 1000 administrative jobs have been cut in local policlinics. $^{34}$ However, this effect is short term, it has stabilized after 2-3 years of service concentration.

The impact of concentration on integration was evaluated with the use of indicators of teamwork, coordination of care and continuity of care. ${ }^{3}$ The study selected four major indicators and explored the results of the abovementioned survey of physicians. The focus of the analysis is to compare the responses of physicians that work in integrated hospital-polyclinic entities ("combined hospitals") with those in independent entities (polyclinics and hospitals).

The first survey question was "How often do polyclinic physicians discuss their pre-admission activities with hospital physicians?" This was used as an indicator of both coordination of care and teamwork. The survey demonstrates that both hospital-polyclinic and independent entities' physicians do this equally seldom or not at all (Figure 2).

The second question "How often do hospital physicians consult polyclinic physicians on patients management after hospital discharge?" is an indicator of continuity of care. The survey demonstrates that physicians of polyclinics, which are the structural units of hospital-polyclinic complexes, receive feedback from physicians of inpatient units even less frequently than their counterparts from independent polyclinics (Figure 3).

The third question "How often does you polyclinic receive the information about hospital admissions of your enrollees?" is an indicator of coordination and continuity of care. Around $50 \%$ of polyclinic physicians do not receive this information at all or receive for $<30 \%$ of hospital admissions. This indicator is equal for physicians of consolidated and non-consolidated entities.

The fourth question is general: "What is your evaluation of the level of interaction between hospitals and polyclinics." Paradoxically, physicians working in formally integrated systems report more often a poor interaction between individual providers $-49 \%$ of respondents relative to $23 \%$ in independent polyclinics (Figure 4).



Physicians of independent city polyclinics $\quad$ Physicians of consolidated hospital-polyclinic city complexes

Figure 2 Physician survey question: how often do polyclinic physicians discuss their pre-admission activities with hospital physicians? (\% of polyclinic physicians working in hospital-polyclinic entities and independent entities). 


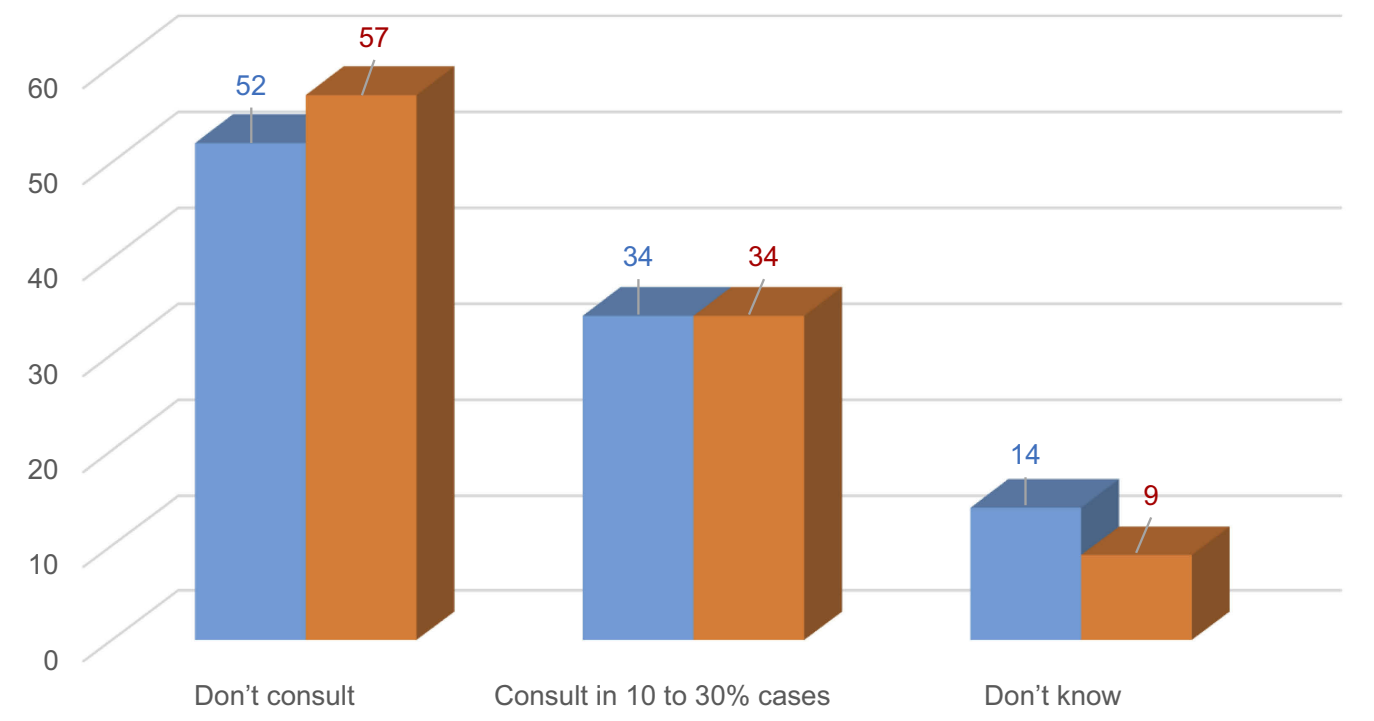

Physicians of independent city polyclinics a Physicians of consolidated hospital-polyclinic city complexes

Figure 3 Physician survey question: how often do hospital physicians consult polyclinic physicians on the tactics of patients management after hospital discharge? (\% of all physicians working in hospital-polyclinic entities and independent entities).

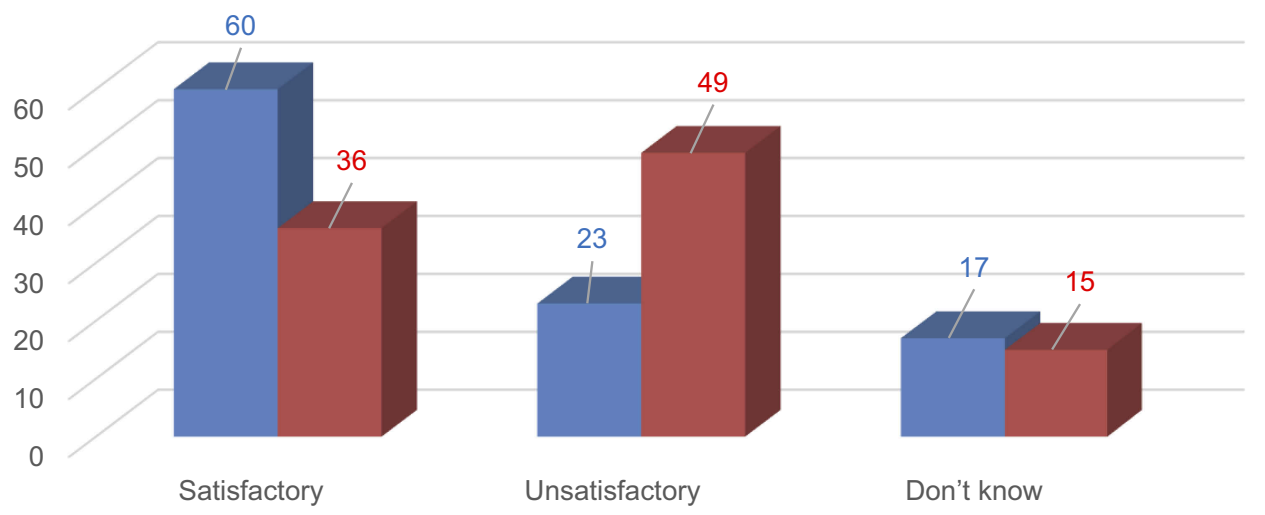

- Physicians of independent city polyclinics $\square$ Physicians of consolidated hospital-polyclinic city complexes

Figure 4 Physician survey question: what is your evaluation of the level of interaction between hospitals and polyclinics (\% of all physicians working in hospital-polyclinic entities and independent entities).

The interviews with managers of outpatient centers and hospital-polyclinic entities in Moscow city demonstrated similar results. All managers spoke about substantial progress in building an integrated medical information system, but managers observed that these systems had not contributed much to the actual interaction between polyclinic and hospital physicians. Formally consolidated systems have not established multidisciplinary teams of providers needed to deal with specific chronic patients. They have not adjusted the national clinical recommendations and integrated patient pathways developed by the
Federal Ministry of Health. Continuity of care after hospital discharge remains a serious problem. ${ }^{36}$

Integration presumes a special role of primary care providers in coordination of care through their "gatekeeping" function. In Russia, there is a special regulatory requirement for patients to see first their DP and then to be referred to specialists. But this requirement does not actually work in practice. $85 \%$ of respondents of the survey of 171 DPs from 14 Russian regions report that their patients see gynecologist directly without referral, $75 \%$ report direct contact with urologist, $70 \%$ - with 
ophthalmologist, 35\% - with neurologists. Therefore, primary care physicians have limited opportunities to coordinate care. Partly this is the result of low comprehensiveness of care provided by DPs. They deal with a limited list of clinical cases, therefore patients tend to see specialists directly. ${ }^{36}$ Merging providers do not change much.

The common argument for health provider concentration is that it enables to centralize information flows and thereby to strengthen the integration of care. All interviewed managers of Moscow medical facilities confirmed this point referring to the increased opportunity to have a unified patient database. But all managers had to admit that physicians rarely used this data for the communication with each other. They agreed with the point that the centralized patient data were necessary but not the adequate condition for the integration.

The evidence-based best practice guidelines for coordinated care are needed. They should include clear rules and algorithms of activities on how to respond to the unified data at each level of service delivery, as well as the performance targets for the teams of workers. For example, patients with a stroke are discharged after admission, but polyclinic physicians rarely know about this admission, and are therefore poorly prepared for the follow-up care activities. Hospitals and polyclinics may form a joint entity and have a unified patients database, but provider behavior change will be minimal without clinical guidelines for meaningful integrative activities.

Mergers of providers have not been combined with the introduction of economic incentives for integration. The current methods of provider payment are based mostly on the reimbursement of volumes of care - physician visits and hospital admissions. The methods of payment for integration, which are increasingly used in Western countries, particularly bundled payment for outpatient-inpatient care and payment for specific integration activities, ${ }^{37}$ are not used in Russia. The prevailing payment methods do not motivate joint provider activities to ensure continuity of care after hospital discharge and do not contribute to the introduction of multidisciplinary teams of polyclinics and hospitals health workers. The economic incentives should be complemented with clear accountability for performance, as well as training and education of staff to work in such teams. There is no evidence of such institutional arrangements in the Russian health care.

\section{Discussion}

The analysis demonstrates the common international interests in health provider concentration. In Western countries, the major drive to achieve more integrated care systems is the establishment of consolidated care delivery systems (hospital and hospital-physicians), while the average size of hospitals remains relatively stable. In Russia, the establishment of consolidated systems is coupled with an increase in the scale of hospitals, while the number of free-standing providers has substantially decreased. The process of concentration in Russia may have reached its limit. With only one provider in the community, it is impossible to continue their mergers unless regions agree to consolidate local hospitals.

The effect of Russian health sector concentration is controversial. There is some evidence of its positive impact on restructuring service delivery and the accessibility of some specialists and expensive diagnostic services, but there is not enough strong evidence of improving the organization of service delivery and strengthening providers' interaction. Some progress is evident in accessibility for some "rare" services, and a decrease in administrative cost is short term. The potential of higher integration in large medical systems has not yet been realized. Similar controversial outcomes of concentration are experienced in the USA. The evidence of its positive impact on integration is limited. Further study on how provider performance can change from enhanced teams and financial incentives for integration is needed.

What are the barriers to integration in consolidated facilities in Russia? The major factor is the lack of clear objectives of health provider concentration. The federal strategy for concentration does not exist. Decisions on mergers are made by regional governments, with a major role of leaders of regional health authorities rather than managers of polyclinics and hospitals. Politicians play a secondary role, while the medical profession is not involved at all. These decisions are driven by concerns to reduce costs and to enable changes in the structure of service delivery rather than to improve the quality of care. The objective of strengthening provider integration is not articulated. Our interviews with managers of consolidated settings indicated a wide range of motives for concentration, of which the most important was an enhanced opportunity to rearrange service delivery, but none of them indicated the objective of improving quality of care and interaction of individual providers. In broader 
terms, the trend is to widen the scope for the "manual" top-down management, which has become popular in the current political context in Russia.

The second barrier (related to the first) is the lack of meaningful integrative activities. Currently, it is presumed that the mere consolidation of medical facilities and the growth of their size will automatically make structural units more collaborative with each other. This is not happening. The results of the study indicate that the coordination role of primary care providers is limited; DPs and specialists are not much involved in joint planning of patients management plans; hospital doctors are not involved in consulting polyclinics physicians on managing patients after discharge; the exchange of information between providers is limited; economic incentives for integration are unavailable; clinical guidelines do not specify activities for coordinated care. Meaningful and consistent work on the functional integration of service delivery has not started. The gap between the processes of concentration and integration in Russia remains wide.

The third barrier is an imbalance in the structure of service delivery. The Russian health system reproduces the weakness of primary health care with the dominance of hospitals. There is a sharp deficit of DPs $-33 \%$ of physicians for adult care and around $10 \%$ for child care. ${ }^{36}$ There is a substantial gap in funding outpatient and inpatient care $-33.2 \%$ and $50.3 \%$ respectively, while the average shares are nearly equal in the OECD countries. ${ }^{38,39}$ The clinical functions (task profiles) of DPs are limited. ${ }^{40}$ Patients do not trust their DPs and tend to see specialists directly (without referrals). Policlinics are poorly involved in planning service delivery. Their "voice" in determining the patterns of interaction with hospitals is not considered enough by health authorities and insurers.

A reasonable policy question: can access to needed services improve without formal consolidation? We think that this is possible and can refer to the experience of diagnostic centers in many regions of Russia that are accessible with referral of polyclinics. With the growing number of such providers, and with their expanding capacity, further mergers of primary care providers may not be needed. Similar pooling of resources without formal mergers is taking place in Great Britain, where neighboring general practices are increasingly working together in multidisciplinary networks, serving around 30,000 to 50,000 people. They offer a wider range of services by pooling some staff and resources, while retaining the personal care and continuity provided by individual practices. ${ }^{41}$
The alternative to formal consolidation of providers is to establish carefully integrated care pathways of patients movement in the network of independent providers. The example of this model in Russia is the program "Urology" that was launched in 2011 in Voronezh oblast. Its focus is on coordination and continuity of urological care by independent providers of urological care, guided by ne care maps. The major integrative activities are the following: closer cooperation of DPs with urologists in the early detection of new cases; rationalization of patients movement in the system through establishing a new layer of service delivery - inter district urology centers; development and implementation of integrated clinical recommendations and pathways; monitoring utilization, quality and cost of care across the integrated network of providers. This innovative model has contributed to a decline in the need for tertiary urological care; a decrease in unit costs of urological cases; as well as a sharp decline in prostate cancer mortality. ${ }^{6}$

Drawing on the results of this study, we can suggest the following recommendations on the management of concentration and integration processes in the context of countries with the limited financial resources.

1. Increase the level of clinical and economic justification for merging health providers with the focus on the achievement of the actual health care integration. Prior to policy to encourage mergers, it is necessary to identify fragmentation barriers in the work of a) individual units of polyclinics (primary care physicians, specialists and diagnostic service), b) polyclinics and hospitals, c) polyclinics and emergency care units, d) hospitals and rehabilitation units, e) clinical and support services. To collect and analyze needed information on patterns of patients' movement across providers, and then to decide on ways to strengthen integration with or without formal mergers of providers.

2. Take into account the location of providers. The merger is justified for providers located not far from each other. In this case, it is easier to build rational patterns of patients' movement across providers who are in close proximity. When they are located too far from each other, it is more difficult to manage the new entity.

3. Appoint a manager responsible for integrative activities in the consolidated facilities. This manager of the integrative activities will show whether additional administrative structures are necessary.

4. Develop at the central level-integrated pathways of patients movement and clinical recommendations with a 
focus on the integrative activities, as well as the procedures for their adjustment in the regions. Each consolidated facility establishes its specific requirements to the interaction of individual structural units by considering problems of fragmentation. This adjustment is particularly important for countries with large regional variance in the organization of health care and resources available. This is particularly true for Russia.

5. Build the information system that supports all units of consolidated facilities. This system is a necessary but not sufficient condition for successful integration. The information system that serves a poor model of service delivery organization can hardly contribute to integration. The specific patterns and requirements for providers' interaction, based on their joint use of information, are essential, especially for:

- quick provision of information on hospital admissions and emergency visits to polyclinics (primary care providers in their staff) for each enrollee, with the instructions on the follow-up activities;

- informing polyclinics physicians by hospital physicians about all diagnostic issues of patients management prior to admission to hospital, as well as the use of inadequate outpatient tests;

- consulting polyclinics physicians by hospital physicians on after discharge activities, particularly for the most complicated cases;

- the joint planning of patients management by primary care physicians and specialists;

- the joint discussion of integrative activities with the involvement of all providers of the consolidated facility.

6. Establish cross-cutting indicators of outcomes for the entire network of clinical structures. For example, the outcome for the case of stroke is not only the removal of the patient from the acute life-threatening condition in a hospital, but also the final improvement of his/her state that is reached by joint efforts of various units.

7. Organize the involvement of polyclinics physician in the work of inpatient units. In Russia, specialists work in the staff of either polyclinic or hospital. The former provide only outpatient care, the latter - only inpatient care. This does not allow outpatient specialists to gain the necessary competence and experience (the term "nonoperating urologist" is often used) Consolidated polyclinic-hospital facilities provide additional opportunities to overcome this separation.
8. Strengthen the coordinating role of general practitioners. They should act as gatekeepers and help patient to choose the right movement in multi-level system of service delivery. Their role is vital for inter-specialty communication of providers.

9. Start payment for integration. As the first step, to pay for additional integrative activities and then to use bundled payment for inpatient care and the follow-up rehabilitation. With the development of chronic disease management programs, to test disease-based bundled payment and shared-sharing schemes. This will motivate providers to work together.

\section{Conclusions}

The analysis demonstrates the universal tendency of health providers concentration in various forms. Contrary to the conceptual expectations, empirical estimates for the USA indicate a controversial impact of concentration on the quality of medical care, unit cost, and integration of care. This assessment suggests that mergers contribute to integration only when specific integrative activities are carefully designed and implemented. Concentration may facilitate this process only when there is a clear-cut national strategy for integration with guidelines and economic incentives for health providers.

In Russia, the results of concentration are also controversial. It facilitates the maneuver with resources and has some positive effect of service restructuring. However, concentration has not contributed to integration due to a number of process barriers. The major lessons learned for countries with limited financial resources are:

1. Consolidation of providers should be carefully justified with a focus on the achievement of the actual integration of service delivery.

2. Specific integrative activities should be planned with cross-cutting indicators of outcomes for the entire network of clinical structures.

3. National health policy for integration is the major pre-condition for the positive impact of concentration on integration.

\section{Ethical corrections}

National Research University High School of Economics (HSE) has a "Commission on the intra university surveys and ethical reviews of empirical research projects" https:// www.hse.ru/org/hse/irb/. This paper is an output of research project implemented as part of the Basic 
Research Program of HSE. The projects under this program do not require approval statement of the commission. Also, the ethical aspects of the survey used in the paper are addressed in the contract between HSE and the Russian Centre for public opinion, which conducted the survey.

\section{Acknowledgments}

This paper is an output of a research project implemented as part of the Basic Research Program at the National Research University Higher School of Economics (HSE) in Moscow, Russia.

\section{Disclosure}

The authors report no conflicts of interest in this work.

\section{References}

1. WHO Study Group on Integration of Health Care Delivery. Integration of Health Care Delivery: Report of WHO Study Group. Geneva: Technical Report Series; 1997:861.

2. Kodner D, Spreeuwenberg C. Integrated care: meaning, logic, applications, and implications - a discussion paper. Int J Integr Care. 2002. www.ncbi.nlm.nih.gov/pmc/articles/PMC1480401/. Accessed, 2002. doi: $10.5334 /$ ijic. 67

3. Sheiman I, Shevski V. Evaluation of health care delivery integration: the case of the Russian Federation. Health Policy. 2014;115(23):128-137. doi:10.1016/j.healthpol.2013.12.011

4. Essential Hospital Institute. Integrated Health Care Literature Review. Washington, DC. 2013.

5. Keshvani P, Walsh A. Physician-hospital integration strategies. Health Care Law Mon. 2013;12:2-8.

6. Apolihin O, Sheiman I, Shishkin S, Katibov M. Building the integrated system of urological services: the impact on utilization and cost of care. Int $J$ Healthcare. 2018;4(2):10-19. doi:10.5430/ijh. $\mathrm{v} 4 \mathrm{n} 2 \mathrm{p} 10$

7. Gerry C, Sheiman I. Too many and too few: the paradoxical case of physicians in the Russian federation. Int $J$ Health Plann Manage. 2018;33(1):391-402.

8. Schmitt M. Do hospital mergers reduce costs? J Health Econ. 2017;52:74-94. doi:10.1016/j.jhealeco.2017.01.007

9. Gaynor M, Laudicella M, Propper C. Can governments do it better? merger mania and hospital outcomes in the english NHS. $J$ Health Econ. 2012;31:528-543. doi:10.1016/j.jhealeco.2012.03.006

10. Nolte E, Pitchforth E, Miani C, McHugh S. The Changing Hospital Landscape. An Exploration of International Experiences. CA, USA: The RAND Corporation; 2014.

11. Rice T, Unruh LY, Rosenau P, Barnes AJ, Saltman RB, van Ginneken E. Challenges facing the United States of America in implementing universal coverage. Bull World Health Organ. 2014;92:894-902. doi:10.2471/BLT.14.141762

12. Palazzolo J, Ozcan Y. Do the most efficient accountable care organizations earn shared savings? Socio-Econ Plann Sci. 2017. doi:10.1016/j.seps.2017.05.001

13. Cuellar E, Gertler P. Strategic integration of hospitals and physicians. $J$ Health Econ. 2006;25(1):1-28. doi:10.1016/j.jhealeco.2005.04.009

14. Enthoven A. What is an Integrated health care financing and Delivery System (IDS)? and what must would-be IDS accomplish to become competitive with them? Health Econ Outcome Res. Open Access. 2016;2:115. doi:10.4172/heor.1000115
15. Cutler D, Morton F. Hospitals, market share, and consolidation. JAMA. 2014;310:1964-1970. doi:10.1001/jama.2013.281675

16. Giancotti M, Guglielmo A, Mauro M. Efficiency and optimal size of hospitals: results of a systematic search. PLOSONE. 2017;12(3). doi:10.1371/journal.pone. 0174533

17. Weeks W, Gottlieb DJ, Nyweide DE, et al. Higher health care quality and bigger savings found at large multispecialty medical groups. Health Aff. 2010;29:991-997. doi:10.1377/hlthaff.2009.0388

18. Shortell S, Schmittdiel J. Prepaid groups and organized delivery systems: promise, performance, and potential. In: Enthoven A, Tollen L, editors. Toward a 21st Century Health System: The Contributions and Promise of Prepaid Group Practice. San Francisco: Jossey-Bass; 2004:1-21.

19. Rittenhouse D, Grumbach K, O’Neil E, Dower C, Bindman A. Physician organization and care management in California: from cottage to Kaiser. Health Aff. 2004;23:51-62. doi:10.1377/hlthaff.23.6.51

20. Hwang W, Chang J, Laclair M, Paz H. Effects of integrated delivery system on cost and quality. Am J Manag Care. 2013;v19:e175-e184.

21. Dranove D, Lindrooth R. Hospital consolidation and costs: another look at the evidence . J Health Econ. 2003;22:983-997. doi:10.1016/ j.jhealeco.2003.05.001

22. Kaul A, Prabha K, Katragadda S Five ways to help healthcare systems realize the benefits of scale. PWC Strategy\&; 2016. Available from: www.strategyand.pwc.com. Accessed June 27, 2019.

23. Fulop N, Protopsaltis G, Hutchings A, et al. Process and impact of mergers of NHS trusts: multicentre case study and management cost analysis. $B M J$. 2002;325:246-253. doi:10.1136/bmj.325.7358.246

24. Posnett J. Is bigger better? Concentration in the provision of secondary care. BMJ. 1999; 319:1063-1065. Available from: https://www.ncbi.nlm. nih.gov/pmc/articles/PMC1116851/. doi:10.1136/bmj.319.7216.1063

25. Cwiek K, Inniger C, Zismer D. Setting the right path and pace for integration. Health Financ Manage.

26. Witt M, Jacobs L. Physician-Hospital Integration in the Era of Health Reforms. Oakland: California HealthCare Foundation; 1910.

27. Keshvani P, Walsh A. Physician-Hospital Integration Strategies. Albany, NY: Health Care Law Monthly; 2013 December.

28. The Region Is an Administrative Unit with the Population Ranging from Half a Million to 11 Million. There are 85 Regions in the Country. Each region consists of municipal communities.

29. Health care resources: the organization for economic co-operation and development. Electronic database Available from: https://stats. oecd.org/index.aspx?queryid=24880. Accessed June 26, 2019

30. Federal Statistical Service of the Russian Federation. Russian. Available from: http://www.gks.ru/wps/wcm/connect/rosstat_main/ros stat/ru/statistics/population/healthcare/. Accessed September 26, 2018.

31. The Russian Federation Ministry of Health. [Resources and Health Facilities Activity. Moscow: Statistical Handbook; 2016. Available from: https://www.fedstat.ru/indicator/31557.do. Accessed September 26, 2018 [in Russian].

32. The average region has 25 municipal communities. The Average Size of the Community Is around 27 Thousand Residents.

33. Moscow oblast Ministry of Health. Korolev City Hospital. [presentation "major Outcomes. 2016"]. Russian; 2017. Unpublished.

34. Moscow City Department of Health. [presentation on the Implementation of the State Program "capital Health Care in 2012-2020"]. Russian; 2015. Unpublished.

35. Somanathan A, Sheiman I, Salakhutdinova S, Buisman L. Universal Health Coverage in Russia: Extending Coverage for the Poor in the Post-Soviet Era Issue 37: Universal Health Coverage Study Series. Washington: The World Bank; 2018.

36. Sheiman I, Shishkin S, Shevsky V. The evolving Semashko model of primary health care: the case of the Russian Federation. Risk Manag Healthc Policy. 2018; 11:209-220. Available from: https:// www.dovepress.com/articles.php?article_id=41993. doi:10.2147/ RMHP.S168399 
37. Tsiachristas A, Dikkers C, Melinde R, Boland M. Rutten-van Mölken Exploring payment schemes used to promote integrated chronic care in Europe. Health Policy. 2013;113:296-304. doi:10.1016/j. healthpol.2013.07.007

38. Flek V. Russian Health Finance Based on Health Accounting System. Russian. Moscow: Booki Vedi; 2015.

39. OECD. Health at a glance: Europe; 2016. Available from: http:// www.oecd-ilibrary.org/social-issues-migration-health/health-at-aglance-europe_23056088. Accessed September 26, 2018.
40. Kringos DE, Boerma WGW, Hutchinson A, Saltman R, eds. Building Primary Care in a Changing Europe the European Observatory on Health Systems and Health Policies. UK: WHO; 2015.

41. Iacobucci G. The rise of primary care networks. BMJ. 2019;364:1304. doi:10.1136/bmj.142

\section{Publish your work in this journal}

Risk Management and Healthcare Policy is an international, peerreviewed, open access journal focusing on all aspects of public health, policy, and preventative measures to promote good health and improve morbidity and mortality in the population. The journal welcomes submitted papers covering original research, basic science, clinical \& epidemiological studies, reviews and evaluations, guidelines, expert opinion and commentary, case reports and extended reports. The manuscript management system is completely online and includes a very quick and fair peer-review system, which is all easy to use. Visit http://www.dovepress.com/testimonials.php to read real quotes from published authors. 